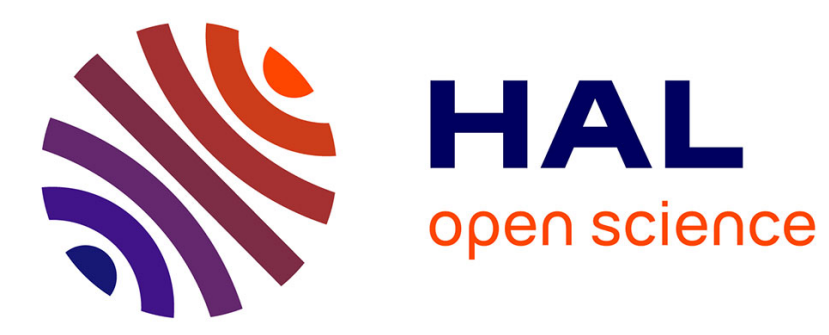

\title{
Cooperative Decision Making: a methodology based on collective preferences aggregation
}

Christophe Sibertin-Blanc, Pascale Zaraté

\section{To cite this version:}

Christophe Sibertin-Blanc, Pascale Zaraté. Cooperative Decision Making: a methodology based on collective preferences aggregation. Group Decision and Negotiation (GDN). Joint INFORMS-GDN and EWG-DSS International Conference, Jun 2014, Toulouse, France. pp. 1-10. hal-01178569

\section{HAL Id: hal-01178569 \\ https://hal.science/hal-01178569}

Submitted on $20 \mathrm{Jul} 2015$

HAL is a multi-disciplinary open access archive for the deposit and dissemination of scientific research documents, whether they are published or not. The documents may come from teaching and research institutions in France or abroad, or from public or private research centers.
L'archive ouverte pluridisciplinaire HAL, est destinée au dépôt et à la diffusion de documents scientifiques de niveau recherche, publiés ou non, émanant des établissements d'enseignement et de recherche français ou étrangers, des laboratoires publics ou privés. 


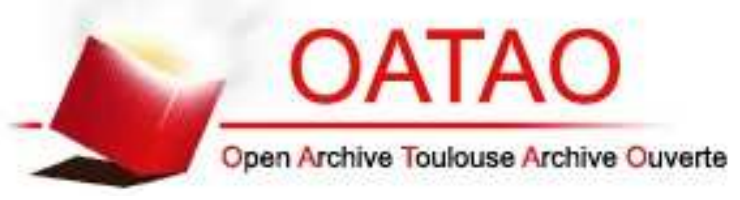

\section{Open Archive TOULOUSE Archive Ouverte (OATAO)}

OATAO is an open access repository that collects the work of Toulouse researchers and makes it freely available over the web where possible.

This is an author-deposited version published in : http://oatao.univ-toulouse.fr/ Eprints ID : 13067

URL: http://dx.doi.org/10.1007/978-3-319-07179-4_1

To cite this version : Sibertin-Blanc, Christophe and Zaraté, Pascale Cooperative Decision Making : a methodology based on collective preferences aggregation. (2014) In: Group Decision and Negotiation (GDN). Joint INFORMS-GDN and EWG-DSS International Conference, 10 June 2014 - 13 June 2014 (Toulouse, France).

Any correspondance concerning this service should be sent to the repository administrator: staff-oatao@listes-diff.inp-toulouse.fr 


\title{
Cooperative Decision Making: A methodology based on Collective Preferences Aggregation
}

\author{
Christophe Sibertin-Blanc ${ }^{1}$, Pascale Zaraté ${ }^{1}$ \\ ${ }^{1}$ Université Toulouse 1 Capitole - IRIT - Faculté d'Informatique, 2 rue du Doyen Gabriel \\ Marty, 31042 Toulouse Cedex 9, France \\ \{ sibertin, Zarate\}@irit.fr
}

\begin{abstract}
The benefice of a collective decisions process mainly rests upon the possibility for the participants to confront their respective points of views. To this end, they must have cognitive and technical tools that ease the sharing of the reasons that motivate their own preferences, while accounting for information and feelings they should keep for their own. The paper presents the basis of such a cooperative decision making methodology that allows sharing information by accurately distinguishing the components of a decision and the steps of its elaboration.
\end{abstract}

Keywords: Cooperative Decision Making, Collective choices, Preferences Aggregation

\section{Introduction}

In most organizations, the vast majority of decisions are taken after intensive consultation with numerous people, rather than by individual decision makers working in larger organizations [1]. In addition, these authors showed that the more complex the organizations become, the less the decisions are taken by lone individuals. According to [2], decision making processes in organizations generally involve several actors in interaction with one another. This interaction implies communication of information and an understanding shared by the decision makers involved in these processes.

The participants in a decision making process must pool their efforts and work towards a common goal, and they have to integrate multiple points of view which may not necessarily be compatible. They have to work together, although not necessarily in the same place or at the same time. They are committed to a coordination effort in order to solve the problem, where they have to divide the task of making the decision into different sub-tasks which will be assigned to individual contributors.

A number of authors have analyzed the process of group decision making from various perspectives. [3] has shown that the use of Information and Communication Technologies in organizations implies a modification of decisional processes. Indeed 
the decisional processes are more complex involving more actors. These modifications are present at two levels; in one hand, at the organizational level, the processes involve more actors at several degrees of responsibilities and in another hand the cognitive processes of decision makers are also modified. They face with an amount of information and must operate an ultra-rapid sorting out of information. New kinds of decision making processes are then defined, called: Cooperative Decision Making.

Several authors have defined cooperation on several points of view. [5] propose to use the definition of cooperative work as a starting point. They characterize cooperative work as people working together, who are mutually dependent for their work and who: support one another in the performance of their respective tasks. This definition is given from the viewpoint of an outside observer of the whole system. Also, a contrario, cooperation can be defined from the point of view of each agent involved in the general process. For [6], cooperation is the way of overcoming individual limitations. Cooperation can also be defined as the set of collective actions finalized and developed to deal with individual limitations. Based on this cooperative paradigm several associated concepts must be defined as coordination and collaboration. Cooperation is richer than collaboration in the sense that a mutual support is generated among the stakeholders. Coordination is the management of dependences involved in all collaboration or cooperation processes (for more details on these concepts see [3]).

Based on this paradigm of decision making, the difficulty for decision makers is to make a balance between their own preferences and the arising common preferences of the group. The objective of this this paper is to propose a methodology for the aggregation of the group's collective preferences and the decision makers' individual preferences. This methodology has for objective to support a facilitator involved in a group decision making process, and is not connected to studies developed in the social choice domain for which the collective decision making process is not supported by a system or a facilitator.

This paper is organized in four parties. The first part is devoted to the introduction of our problematic. In a second part, we introduce two kinds of works on which our research is based: a. the Group decision Making tools and the process to use them and b. works coming from tools for social simulation for which the data, hypothesis and methodologies of preferences aggregations are defined.

\section{Methodology Context}

The proposed methodology is based on several works about group decision making tools.

\subsection{Tools for Group Decision Making}

Group Decision Support Systems (GDSS) are a widely used collaborative technology that has proven to increase user participation and the quality of decision- 
making. They are intended to provide computational support to collaborative decision-making processes [7].

In virtual organizations, GDSSs seem extremely adequate to improve strategic decisions made at the upper levels of the organizational structures, through better information acquisition, perception of different perspectives and options, and consensus formation. This thread leads to an increasing presence of GDSSs in organizations. Thus the facilitation activities must accompany such movement and the facilitator's interest is also kept (see [4]).

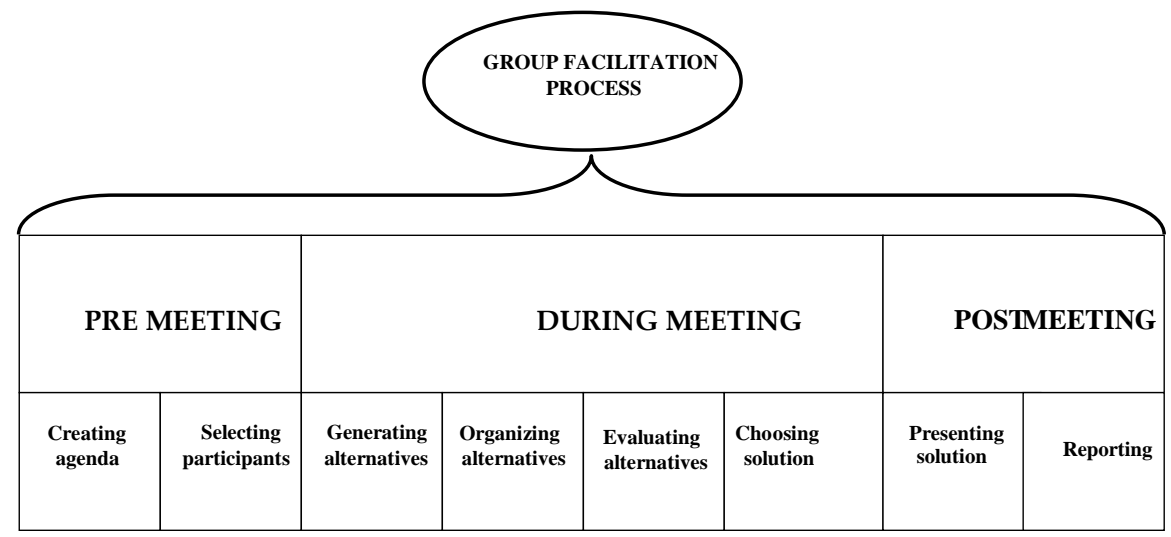

Fig 1: Group facilitation process

[8] proposed a methodology to use PROMETHEE MCDA systems in a group decision making context. They propose that every decision makers fulfil their own individual preferences in a performances matrix. Then a global evaluation of each alternative is performed thanks to weighted sum aggregation technic. The decision makers could have the same weight or different weights. This is certainly very interesting in order to conduct a sensitive analysis among the stakeholders. Nevertheless, the decision makers have no possibility to share with the other participants their preferences or to co-built a decision. Our purpose is to propose a methodology for decision makers' preferences aggregation in a collaborative way. It means that the decision is co-built by the participants; they exchange their viewpoints trying to design a common representation of the problem at hand and then to reach an agreement or a consensus. It does not imply that all decision makers must share all criteria, preferences and weights, in another words all parameters of the decision. In our approach, the decision makers will agree on several criteria that are called collective criteria but they also can defend individual criteria that are personal to each stakeholder. We develop a methodology able to aggregate individual preferences as well as collective preferences.

To achieve this objective our proposal is based on a procedure able to support the participants in the sharing of information. 


\subsection{Group Decision Making Hypothesis}

One dimension of any group decisions process is sharing information that supports the participants' preferences. The participants may announce their preferred alternative without providing each other arguments about the appropriateness of this alternative to solve the problem at hand. In this case, the decision process does not contribute to a deeper understanding of the problem, a better knowledge of the alternatives and the possible matches between the two. The decision does not benefit from being taken by a group (on the concept of cooperation see [5]. Thus the drivers of the final decision (if any) are not to be searched among the qualities of the alternatives but in exogenous factors like the organizational or social relationships between the participants. On the opposite case, participants may reveal to others all the reasons that justify their preferences while fully explaining the means-ends chain that leads to their choice. In this case, the decision process is the opportunity to investigate the matches between the problem and the alternatives as much as enabled by the participants' abilities, and the final decision will be fully rationalized by the coherent exposure of all the arguments in its favor. However, this way of doing is seldom practicable first because participants have personal information or considerations that they will not (strategic reasons) or may not (for privacy reasons) to be public and second because some reasons of their own preference are not so much crystal clear to themselves.

So a decision-making process methodology must account for the level of information sharing that is the most relevant with respect to the nature of the decision, the position of the participants and more globally the context of the decision process. Several level of information sharing can be considered: (1) information that results from discussion among the participants and are commonly agreed by them; they are considered as objective facts, so that no argument contradicting them should be considered; (2) information that is the own opinion of one of the participants and told to other as such and so are not assumed to be agreed upon by others; these information shed light on the preference stated by the actor but are not part of the participants common agreement; (3) information that are proper to one participant and that he does not make known by others. When using a GDSS, the facilitator should have the possibility to parameterize the tool that supports the decision process to adapt the sharing of information to the context.

It is very common that the group entrusted to take a decision includes on the one hand experts who have a good technical knowledge of the domain and of issues regarding the alternatives to be examined and, one the other one, people who are more versed in the problem side of the decision and will more or less bear the duty and be concerned by the consequences of the decision (e.g. the work to be done to implement the decision, the justification of the decision to stakeholders absent of the decision process, or the entailed changes in his own practice or in the practice of people he is related to). This is not a strict separation since each participant can position himself more or less as an expert or as concerned (or affected) by the decision, but these two roles, these two ways to contribute to the decision-making process, must be considered.

To this end, we propose to distinguish two stages in elaborating the ranking of the alternatives with regard to their relevance as a solution: first the scoring of 
alternatives with regard to the criteria used for their evaluation and second the suitability of a given scoring to fulfil the need of the problem. The scoring of alternatives is mainly a matter for experts because they are likely to be more experienced in the examination of such alternatives and to have a better (wider and deeper) knowledge of the domain thanks, among others, to interactions within their professional community. As for deciding whether the score of an alternative makes it more or less suitable for the problem, it is rather a matter for the concerned participants who have a better knowledge of the concrete problem, could consider many constraints (most often much more numerous than the criteria) related to details that can reveal to be of importance or can have a temporal perspective about the history and the becoming of the problem.

\section{The proposed methodology}

\subsection{The group decision-making setting}

As an illustrative example, consider the selection of a new collaborative platform intended to support the communications and coordination among the employees of a company spread between different sites [9]. The choice is to be made by a group of five participants $\mathrm{G}=\left\{\mathrm{p}_{1}, \ldots \mathrm{p}_{5}\right\}$ including two managers representative of the company, one software engineer from a partner company and two academicians, who have to rank a set of eight pre-selected software, the alternatives $A=\left\{a_{1}, \ldots, a_{8}\right\}$, according to the quality of the solution they bring to the considered needs.

Four criteria are considered to evaluate the platforms:

- Functionality: it considers the functions related to collaboration (e-mail, calendar, forum, ...), each one with its importance weight. The score of an alternative is the total weight of the offered functions over a scale of 100 .

- Cost of the exploitation license per person and per year.

- $\quad I H M$, the Human-Machine Interface (administration simplicity, usability).

- Perenniality of the software editor company and the product itself with regard to its position on the market.

Each alternative is amenable to be evaluated on a scoring scale which is either a numerical interval (e.g. functionality and cost) or a qualitative ordinal scale (e.g. IHM and perenniality). In this latter case, each value of the scale must be associated with a description, as much unambiguous as possible, of the characteristics and qualities of an alternative that gets this mark. Low values are assumed to correspond to characteristics that poorly satisfy the criterion and higher values to characteristics that satisfy it increasingly better. But this does not prevent a participant to have an inversed scale of preference and to consider that low values fit better the needs than high values 
For each criteria that is considered, we assume that each participant is able to define a suitability function that determines how much each value of the scoring scale of this criterion makes an alternative suitable as a solution, the scale of suitability being the same for all criteria and participant, for instance the interval $[-10,10]$. A null suitability for a criterion means that the criterion is fulfilled at an acceptable level which does not particularly recommend or disqualify the alternative; more the suitability over a criterion is high, more the alternative is a good choice, and the converse for negative suitability values ${ }^{1}$. To define the suitability function over a criterion of a participant, he could be asked to indicate, within the scoring scale of the criterion:

- the neutral score that provides a null suitability;

- the indifference score beyond which a higher value does not increase the suitability;

- the reject score below which an alternative is definitely not an appropriate choice;

- the shape of the interpolation between the reject and indifference scores; it can be linear if the increase in suitability is proportional to the increase of the score (cf. figure 2.a), sigmoid if the transition between unsuitability and suitability is prompt (cf. figure 2.b), or if there is a plateau in the improvement of the suitability (cf. figure 2.c).

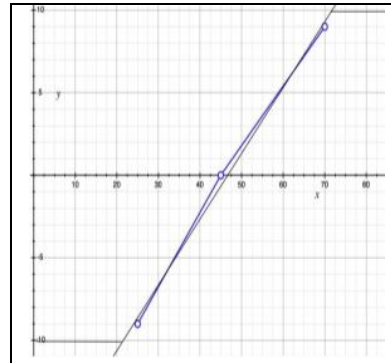

(a) linear improvement of the suitability

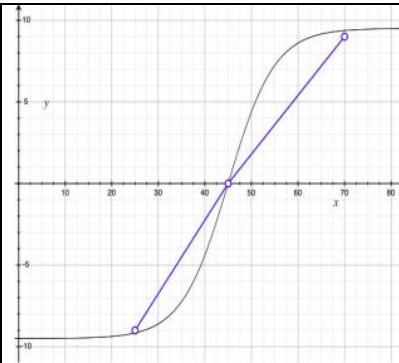

(b) sigmoide improvement of the suitability

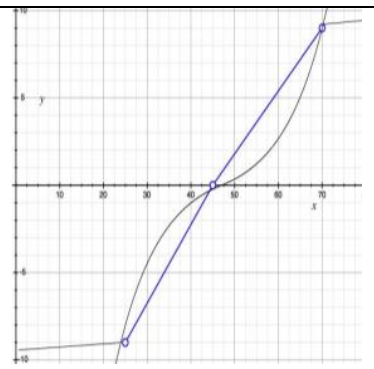

(c) plateau improvement of the suitability

Fig. 2: various shape of the suitability function for the Functionality criterion, where reject score $=25$, neutral score $=45$ and indifference score $=70$

Moreover, each participant, according to the relative importance he recognizes to each criterion, ranks the criteria by allocating to each of them a weight, every actor having the same total of weights to distribute, for instance 10. A criterion that is weighted by a not null value by a single participant is an individual criterion while others are qualified as common criteria.

Then, the following notations are used:

\footnotetext{
1 [10], confirmed by [11], show that people makes more firm evaluations when they have neutral reference point.
} 
$\operatorname{score}_{p}(a, c)$ the score of alternative $a$ on the criterion $c$ for the participant $p$, $w_{p}(c)$ the weight of criterion $c$ for the participant $p$,

$\operatorname{suit}_{p}^{c}(x)$ the suitability function of participant $p$ for the criteria $c$.

The assessment of an alternative $a$ by a participant $p$ will then be defined as:

$\operatorname{assess}_{p}(a)=\sum_{c \in C} w_{p}(c) * \operatorname{suit}_{p}^{c}(\operatorname{score}(a, c))$

where $C$ is the set of all the individual criteria, and the assessment of an alternative $a$ by the whole group of decision-makers as:

$\operatorname{assess}(a)=\sum_{p \in G} \operatorname{assess}_{p}(a)$.

Based on these notations, we propose the following methodology in order to take into account the collective preferences and the individual preferences.

\subsection{Proposed Methodology}

This methodology aims to allow participants to agree on a set of criteria but also to have their own preferences on some criteria and to share at a more small or large extent the reasons of their choice. This methodology is composed by 7 steps.

Step 1:

After discussion, each stakeholder agrees on the collective criteria. It implies that they find an agreement on the relevant criteria, the scoring scale of each criterion and the score of each alternative for each of these criteria. This assumes that the participants are able to measure the characteristics of each alternative in a quite objective way.

Step 2:

Each participant defines and enters into the GDSS:

- His own weights for the collective criteria and possibly also for additional individual criteria.

- His own suitability functions for all criteria to which it attributes a not null weight.

In the following, we suppose that the individual criteria or preferences are fully private and not shown to the group. However, it could be that a participant introduces a new criterion and wishes it to be known by others and such treated as the collective criteria.

Step 3:

The system computes:

- The global weight and the standard deviation of each collective criterion. This weight will be the sum of all weights assigned by all participants.

- The global suitability function of each collective criterion. This global suitability function is the mean of the suitability function of the participants.

- The global suitability of each alternative on each collective criterion: $\operatorname{suitability}^{c}(a)=1 / 5 * \sum_{p} \in G w_{p}(c) * \operatorname{suit}_{p}{ }^{c}(\operatorname{score}(a, c))$. This global suitability is the mean of the assessments (i.e. the weighted suitability) of the participants. 
Step 4:

In this step, the criteria are considered independently one another. The system shows the global weight and the global suitability function of each collective criterion. If all the participants agree, it can also show for each criterion the distribution of the weights in the form of boxplots and also the dispersion (min and max value at each point of the scoring scale) of the global suitability function.

The system then provides information about the application of weights and suitability to the score of alternatives. It shows the gap between the global suitability of each alternative on collective criterion and the individual suitability of each alternative on individual criteria of each participant. The idea of this visualization is to see if the group forms a barycenter and the position of each participant. During this step the visualization is possible by participants or by alternatives.

Step 5:

The participants can then enter in a discussion step in order to clarify their preferences with regard to criteria. The group can then come back to the steps 1 or 2 in order to remove ambiguities; if the group is satisfied with the results then next step can be proceed.

Step 6:

All preferences are then aggregated: the individual preferences as well as the collective preferences thank to the weighted sum aggregation procedure.

Step 7:

This procedure is finished when the criteria of stop are achieved. These criteria of stop must be parameterized in the system and are based on two criteria: satisfactory level of participants and/or the deadline to make the decision is passed.

The steps of this methodology are shown in the figure 3 . The blue steps represent the steps for which a discussion among the stakeholders is engaged. The green step represents a step for which the decision makers give their own preferences in a private way. The purple steps are those for which the system calculate all the necessarily results.

\section{Conclusion and Perspectives}

In this paper we proposed a methodology for supporting a group decision making process, as the first step toward the development of a group decision support system. This methodology is based on two levels of criteria evaluations: collective criteria and individual criteria. This methodology distinguishes the evaluation of alternatives on these criteria (their score), the weights of criteria and the suitability of a score for a solution to the problem addressed by the decision making process. This structuration of individual preferences favors the sharing of information while respecting the privacy of some individual preferences, and so it allows participants to engage in a co-decision making process to build a shared decision. This methodology will be implemented in a Group Decision Support System, in the JAVA programming language.

The proposed aggregation techniques are very simple and so it is very easy for each participant to understand how the GDSS processes the information he gives. The 
GDSS does not appear as a black-box and this foster the participants' adhesion to the final decision. However, these aggregation techniques could be refined depending of the kind of groups and of decisions. Another point to investigate is to consider in which cases reject score could intervene as veto thresholds. These two elements will be investigated as perspective of this work. This work can be investigated as perspectives.

\section{References}

1. Gorry G., Scott Morton M.: A framework for management information systems. Sloan Management Review, Vol 13, N 1, pp. 50-70 (1971)

2. Smoliar S., Sprague R.: Communication and Understanding for Decision Support. Proceedings of the International Conference IFIP TC8/WG8.3, Cork, Ireland, pp. 107-119 (2002)

3. Zaraté P.: Tools for Collaborative Decision-Making. John Wiley (2013)

4. Adla A., Zaraté P., Soubie J.L.: A Proposal of Toolkit for GDSS Facilitators. Group Decision and Negotiation, Springer, Vol. 20, $\mathrm{N}^{\circ}$ 1, pp. 57-77 (2011)

5. Schmidt K. and Bannon L.: Taking CSCW Seriously : Supporting Articulation Work. Computer Supported Cooperative Work (CSCW), Vol 1, No 1 (1992)

6. de Terssac G., Maggi B.: Autonomie et Conception. In de Terssac G. et Friedberg E. (Eds) Coopération et Conception. Octaves Edition, ISBN : 2-906769-33-9 (1996)

7. Nunamaker J., Briggs R.O., Mittleman D., Vogel D., Balthazard P.: Lessons from a dozen years of group support systems research: a discussion of lab and field findings. Journal of Management Information Systems, Vol. 13, N 3, pp. 163-207 (1997)

8. Macharis C., Brans J.P., Maréchal B.: The GDSS PROMETHEE Procedure. Journal of Decision Systems, Vol. 7 -SI, pp. 283-307 (1998)

9. Soner Kara, S., Cheikhrouhou, N.: A multi criteria group decisions making approach for collaborative selection problem. Journal of Intelligent and Fuzzy Systems 26 (1), IOS Press (2014)

10. Slovic P., Finucane M., Peters E., MacGregor D.G.: The affect heuristic, in: T. Gilovitch, D. Griffin, D. Kahneman (Eds.), Heuristics and Biases: The Psychology of Intuitive Judgment, Cambridge University Press, Cambridge, pp. 397-420 (2002)

11. Labreuche, C., Grabisch, M. : Generalized Choquet-like aggregation functions for handling bipolar scales, European Journal of Operational Research 172, pp. 931-955 (2006) 


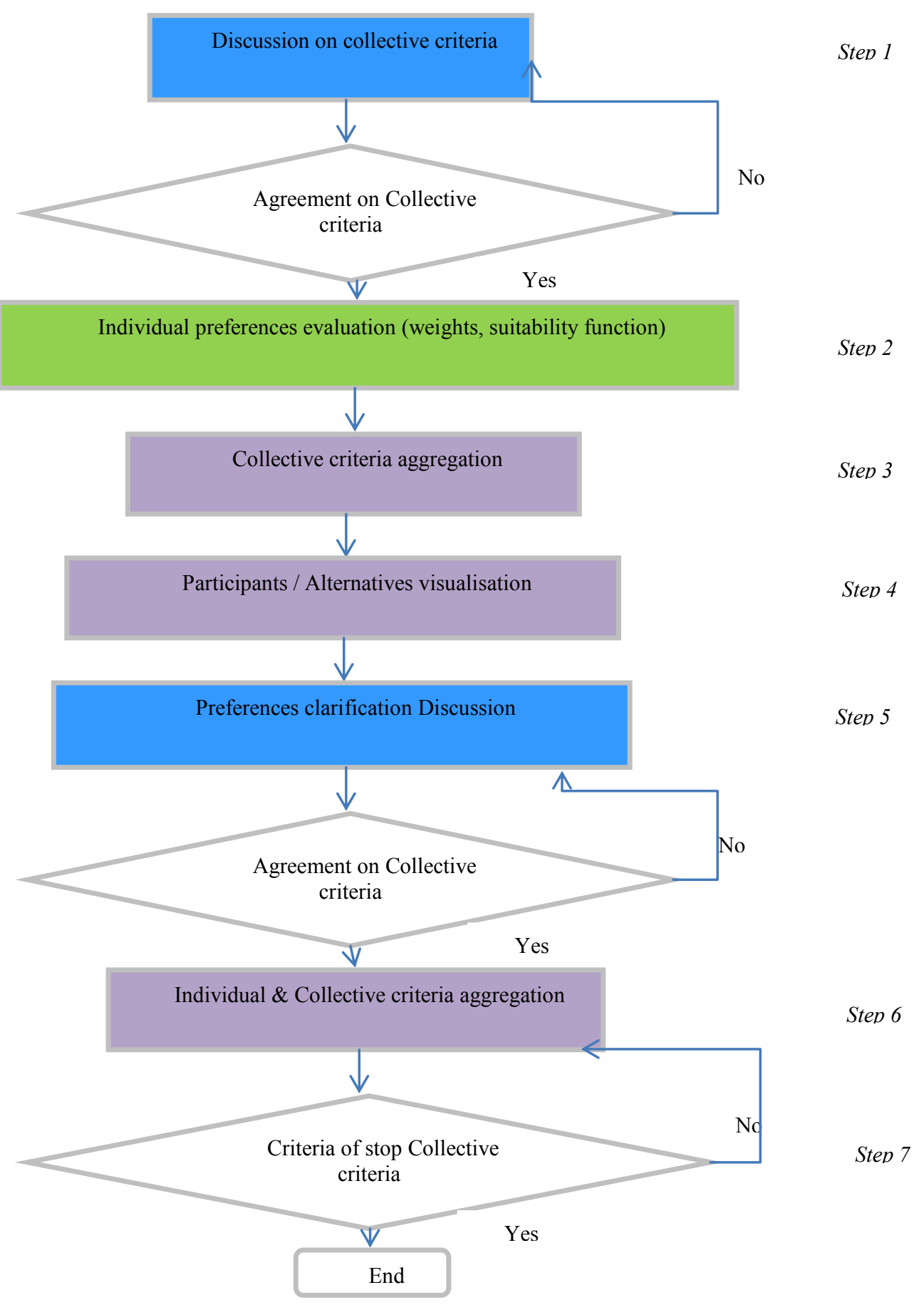

